\title{
ESTUDO PRELIMINAR DAS EMISSÕES DE ALDEÍDOS TOTAIS EM MOTOCICLETAS DE VÁRIAS CILINDRADAS UTILIZANDO O NOVO CICLO DE EMISSÕES CONFORME O PROMOT IV (WMTC) E A NOVA PROPOSTA DO PROJETO DE NORMA DE ALDEÍDOS EM MOTOS BASEADO NA ABNT NBR 12026
}

\author{
Cláudia R. S. Geraldi ${ }^{1}$, Gino Montanari ${ }^{1}$, Marcello Depieri ${ }^{1}$ e Raphael Sedano ${ }^{1}$ \\ ${ }^{1}$ Magneti Marelli Sistemas Automotivos \\ E-mails: claudia.silva@magnetimarelli.com, gino.montanari@magnetimarelli.com, \\ marcello.depieri@magnetimarelli.com, raphael.sedano@magnetimarelli.com,
}

\section{RESUMO}

A fase 4 do PROMOT adotou desde o dia $1^{\circ}$ de janeiro de 2014, o ciclo WMTC Word Motorcycle Test Cycle em substituição ao ciclo europeu ECE R40. Diante da escassez de dados de emissões de aldeidos totais das motocicletas para este ciclo, foi proposto um estudo que demonstrasse preliminamente os valores de emissões encontrados nas várias motocicletas ensaiadas dentro do Laboratório de Emissões Veiculares.

O presente trabalho tem como objetivo, quantificar os aldeídos totais conforme 0 projeto de norma de aldeídos em motos que foi baseado na ABNT NBR 12026 seguindo o ciclo WMTC. Os aldeídos totais quantificados foram obtidos em diversas motocicletas de cilindradas variadas em diversas situações, tais como, ensaios de desenvolvimento, pré - homologações e homologações.

A metodologia empregada utilizou o projeto de norma para a determinação de aldeídos contidos no gás de escapamento de motos por Cromatografia Líquida pelo método DNPH. Este projeto de norma foi baseado na ABNT NBR 12026, seguindo o ciclo WMTC em vigor, conforme determinado pela Legislação Brasileira. que se encontra em fase final de discussão para implementação no Brasil.

Os resultados obtidos serão demonstrados como indicativo inicial das emissões de aldeídos totais para o segmento de duas rodas, já que este poluente não é controlado atualmente pela Legislação Brasileira.

\section{INTRODUÇÃO}

Os aldeídos totais emitidos por fontes móveis (tais como, veículos movidos a Gasolina, Etanol ou Flex) são considerados poluentes secundários, porém com 
grande influência no potencial de formação do gás ozônio $\left(\mathrm{O}_{3}\right)$ troposférico baixo e na formação do composto PAN (nitrato de peróxiacetila).

São controlados em veículos leves com motores do Ciclo Otto desde 1992, através do PROCONVE [1] - Programa de Controle da Poluição do Ar por Veículos Automotores, por meio da Resolução CONAMA ํo.03/1989 [2].

Desde o ínicio até hoje, houve uma dimuinuição drástica nos limites estabelecidos pelo programa. Atualmente, o PROCONVE [1] se encontra na fase 6 (L6), sendo que os limites estabelecidos foram fixados em $0,02 \mathrm{~g} / \mathrm{km}$. Já para os motociclos, similares e ciclomotores, o programa implementado para controle das suas emissões foi o PROMOT [3]. A regulamentação dos limites de emissões para os aldeídos totais ainda não foi definida.

O PROMOT [3] foi estabelecido no Brasil, através da Resolução oㅡ 297/2002 [3], baseada na Diretiva das Comunidades Européias no $87 / 24 /$ EC [4]. Foi a partir de 2003 que os limites propostos passaram a ser vigentes.

O PROMOT [3] foi dividido em fases, assim como também havia sido feito com o PROCONVE [1]. Atualmente, o PROMOT [3] se encontra na fase 4 ou M4, conforme estabelecido na Resolução no 432 de 13 de julho de 2011 [5].

Nesta fase, foram estabelecidos novos limites de emissões bem como também foi prevista a mudança do ciclo de condução, conforme definido na regulamentação da Comunidade Européia - ECE/TRANS/180/Add2 [6], ou seja, a implementação do ciclo WMTC. Atualmente, em vigência está a ABNT NBR 16369 [7] que segue os preceitos da regulamentação européia.

Na Tabela 1 abaixo, são informados os limites de emissões do PROMOT M4:

Tabela 1: Limites de Emissões para Motociclos, Similares e Ciclomotores [4]

\begin{tabular}{|c|c|c|c|c|c|c|}
\hline \multirow[b]{2}{*}{ Categoria } & \multirow[b]{2}{*}{ Data da Vigência } & \multirow[b]{2}{*}{$\begin{array}{l}\text { Velocidade } \\
\text { Máxima }\end{array}$} & \multicolumn{4}{|c|}{ Limites } \\
\hline & & & $\begin{array}{c}\mathrm{CO} \\
(\mathrm{g} / \mathrm{km})\end{array}$ & $\begin{array}{c}\mathrm{HC} \\
(\mathrm{g} / \mathrm{km})\end{array}$ & $\begin{array}{c}\mathrm{NO}_{\mathrm{x}} \\
(\mathrm{g} / \mathrm{km})\end{array}$ & $\begin{array}{c}\mathrm{CO}_{2} \\
(\mathrm{~g} / \mathrm{km})\end{array}$ \\
\hline \multirow{4}{*}{$\begin{array}{l}\text { Motociclos e } \\
\text { Similares }\end{array}$} & \multirow{2}{*}{ 01/01/2014 } & $<130 \mathrm{~km} / \mathrm{h}$ & 2,0 & 0,8 & 0,15 & \\
\hline & & $\geq 130 \mathrm{~km} / \mathrm{h}$ & 2,0 & 0,3 & 0,15 & \\
\hline & \multirow{2}{*}{$01 / 01 / 2016$} & $<130 \mathrm{~km} / \mathrm{h}$ & 2,0 & 0,56 & 0,13 & \multirow{3}{*}{ Informar } \\
\hline & & $\geq 130 \mathrm{~km} / \mathrm{h}$ & 2,0 & 0,25 & 0,17 & \\
\hline Ciclomotores & 01/01/2014 & & 1,0 & 0,8 & 0,15 & \\
\hline
\end{tabular}

Neste estudo preliminar, não foram coletados os aldeídos totais dos ciclomotores.

\section{O CICLO WMTC}

O ciclo WMTC é composto por três diferentes fases com duração de 600 segundos cada, conforme mostra a Figura 1 abaixo: 


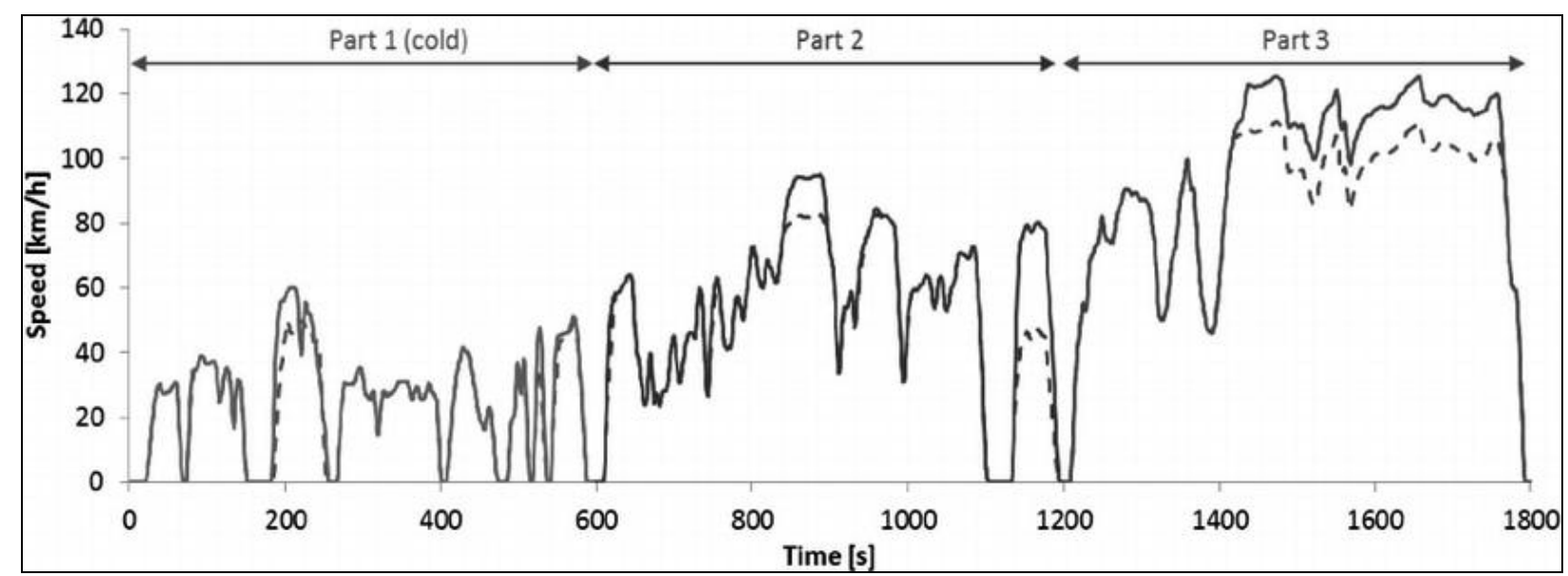

Figura 1: Ciclo de condução para motociclos

O ciclo WMTC classifica as motocicletas, conforme a velocidade máxima atingida e a cilindrada. Dependendo destas condições, as motocicletas são segregadas por classes conforme estabelecido pela regulamentação do WMTC, o tipo de ciclo a ser utilizado e os fatores de ponderação para o cálculo das emissões em gramas por quilomêtro, conforme Tabela 2, abaixo:

Tabela 2: Classes dos ciclos e seus fatores de Ponderação

\begin{tabular}{|c|c|c|c|}
\hline Classe & Tipo de Ciclo & \multicolumn{2}{|c|}{ W (ponderação) } \\
\hline \multirow{2}{*}{1} & Ciclo 1 - C1 & W1 & $50 \%$ \\
& $\mathrm{R} 1+\mathrm{W} 1+\mathrm{R} 1$ quente $\times \mathrm{W} 1$ quente & $\mathrm{W} 1$ quente & $50 \%$ \\
\hline \multirow{2}{*}{2} & Ciclo 2 - C2 & $\mathrm{W} 1$ & $30 \%$ \\
& $\mathrm{R} 1+\mathrm{W} 1+\mathrm{R} 2 \times \mathrm{W} 2$ & $\mathrm{~W} 2$ & $70 \%$ \\
\hline \multirow{3}{*}{3} & Ciclo 3 - C3 & $\mathrm{W} 1$ & $25 \%$ \\
& $\mathrm{R} 1+\mathrm{W} 1+\mathrm{R} 2 \times \mathrm{W} 2+\mathrm{R} 3 \times \mathrm{W} 3$ & $\mathrm{~W} 2$ & $50 \%$ \\
& & $\mathrm{~W} 3$ & $25 \%$ \\
\hline
\end{tabular}

As motocicletas utilizadas nesse estudo se enquadram nos ciclos 1 e 3 do WMTC.

Nesse presente trabalho foram levantados valores de aldeídos totais e individuais para uma classe de veículos que ainda não tem um limite definido e assim poder quantificá-los para conhecimento dos níveis de emissões de aldeídos nos novos ciclos de condução.

Foram comparados os dados obtidos das emissões de aldeídos totais das motocicletas ensaiadas contra o limite em vigor dos veículos leves, a fim de se verificar se as mesmas atenderiam ou não ao limite atual. 


\section{METODOLOGIA}

Foram realizados ensaios em 9 motocicletas, de variadas cilindradas e diferentes sistemas de alimentação, todas movidas a gasolina padrão emissões L6 com $22 \%$ de etanol anidro de referência (Gasool A22), conforme recomendação da norma ABNT NBR 8689 [8].

Os ciclos dinamométricos foram executados no dinamômetro de chassi - AVL Zoellner, próprio para ensaios em motocicletas. Os gases da exaustão foram coletados pelo sistema de amostragem de Volume Constante por Venturi Crítico AVL - (CVS i60) e os gases emitidos diluídos foram detectados pelas bancadas de análises de gases AVL - (AMA i60), com detectores especificos para cada gás amostrado. A quantificação das emissões exaustivas foi executada pelo sistema de aquisição de dados - AVL - GEM201.

A amostragem dos aldeídos totais foi realizada simultaneamente com a dos gases de exaustão, conforme prescrito no projeto de norma para determinação de aldeídos em motocicletas e a norma ABNT NBR 12026 [9]. Conforme mostra a Figura 2 abaixo:

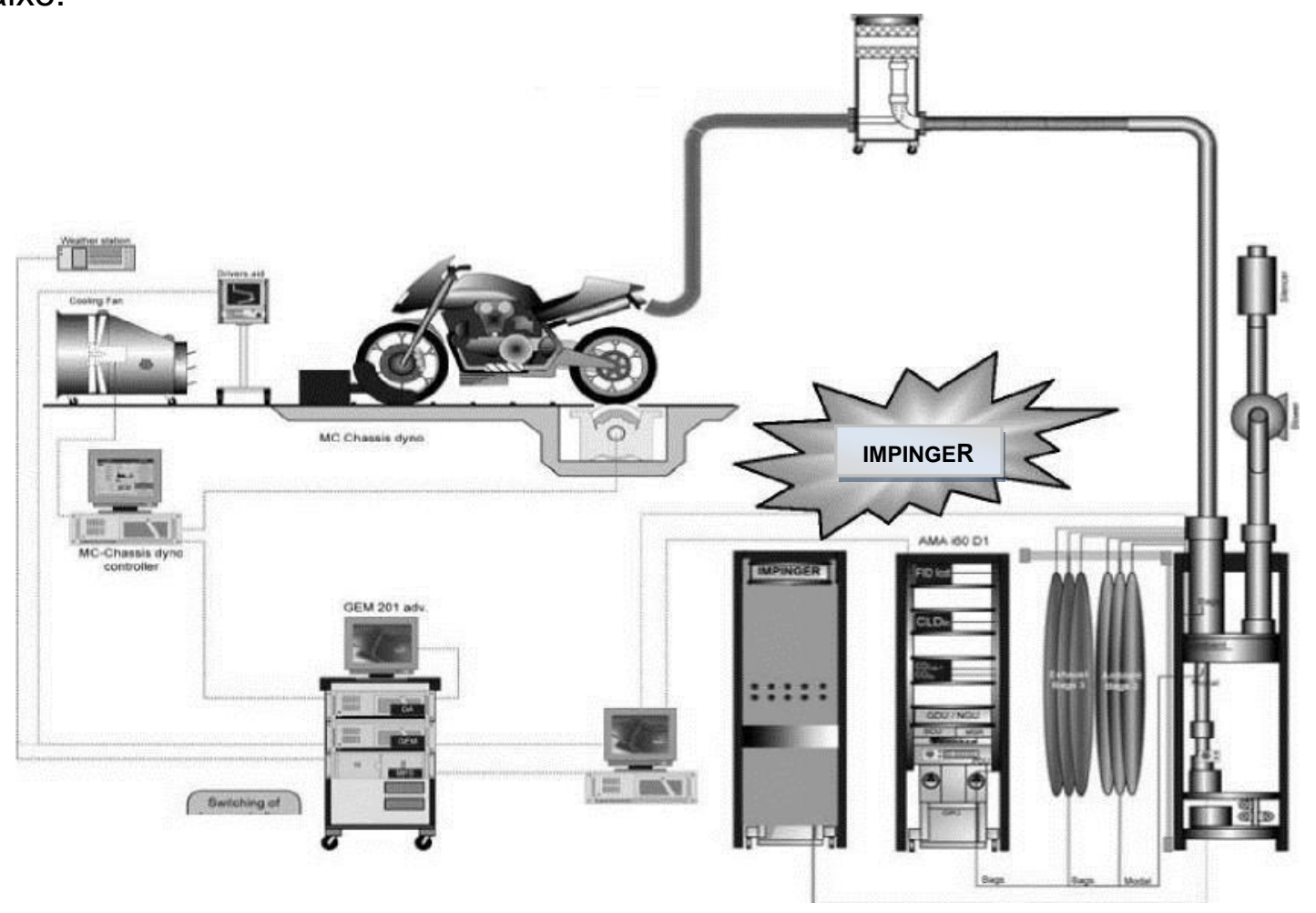

Figura 2: Esquema de ensaio de emissões de poluentes, com coleta de aldeídos

O equipamento utilizado para amostragem dos aldeídos foi o amostrador de gases da marca Horiba dotado com sistema de controle Napro.

As amostras obtidas das motocicletas foram então quantificadas individualmente em compostos derivados carbonílicos (formaldeído e acetaldeído) por Cromatografia Líquida de Alta Eficiência (HPLC) ou (CLAE). O equipamento e software para aquisição de dados utilizados foram da marca Agilent Technologies. 
Todas as condições de tratamento das amostras, reagentes e condições de análise seguiram a recomendação do projeto de norma de aldeídos em motos bem como também da norma ABNT NBR 12026 [9].

Os dados obtidos foram lançados em uma planilha de cálculo para obtenção das emissões de aldeídos individuais (formaldeído e acetaldeido) e totais em gramas por quilômetro. As ponderações das emissões de aldeídos seguiram o prescrito pelo projeto de norma e foram calculadas conforme o tipo de ciclo que foi ensaiada cada motocicleta.

As motocicletas foram divididas em Pequenas, Médias e Grandes Cilindradas para otimização dos dados obtidos.

\section{DISCUSSÃO E RESULTADOS}

As motocicletas para este estudo foram agrupadas de acordo com a Tabela 3, abaixo:

Tabela 3: Classificação das Motocicletas quanto a cilindrada

\begin{tabular}{|c|c|}
\hline Classificação & Cilindrada \\
\hline Pequena Cilindrada & abaixo de $300 \mathrm{cc}$ \\
\hline Média Cilindrada & acima de $300 \mathrm{cc}$ \\
\hline Grande Cilindrada & acima de $800 \mathrm{cc}$ \\
\hline
\end{tabular}

As médias das motocicletas ensaiadas de cada cilindrada foram obtidas e classificadas de acordo com a Tabela 3 acima.

$\mathrm{Na}$ Tabela 4 abaixo, os resultados obtidos de aldeídos totais em gramas por quilômetro das motocicletas ensaiadas após a definição da sua classificação:

Tabela 4: Resultados obtidos de aldeídos totais das motocicletas ensaiadas

\begin{tabular}{|c|c|}
\hline $\begin{array}{c}\text { Categoria } \\
\text { Motocicleta }\end{array}$ & $\begin{array}{c}\text { Aldeidos } \\
\text { Totais }(\mathrm{g} / \mathrm{km})\end{array}$ \\
\hline & 0,0027 \\
Pequena Cilindrada & 0,0024 \\
& 0,0051 \\
\hline Média Cilindrada & 0,0012 \\
& 0,0037 \\
Grande Cilindrada & 0,0022 \\
\hline & 0,0042 \\
& 0,0029 \\
\hline
\end{tabular}

A Tabela 4 mostra que houve uma tendência das motocicletas de grande cilindrada emitirem uma maior quantidade de aldeídos totais, quando comparadas com as 
motocicletas de média cilindrada e grande parte das motocicletas de pequena cilindrada, os valores variaram de 0,0053 a $0,0042 \mathrm{~g} / \mathrm{km}$.

Pode-se notar também que uma parte das motocicletas de pequena cilindrada obtiveram o $2^{\circ}$ maior valor de emissão de aldeídos totais em relação as demais.

A Figura 3 abaixo, mostra graficamente estas diferenças.

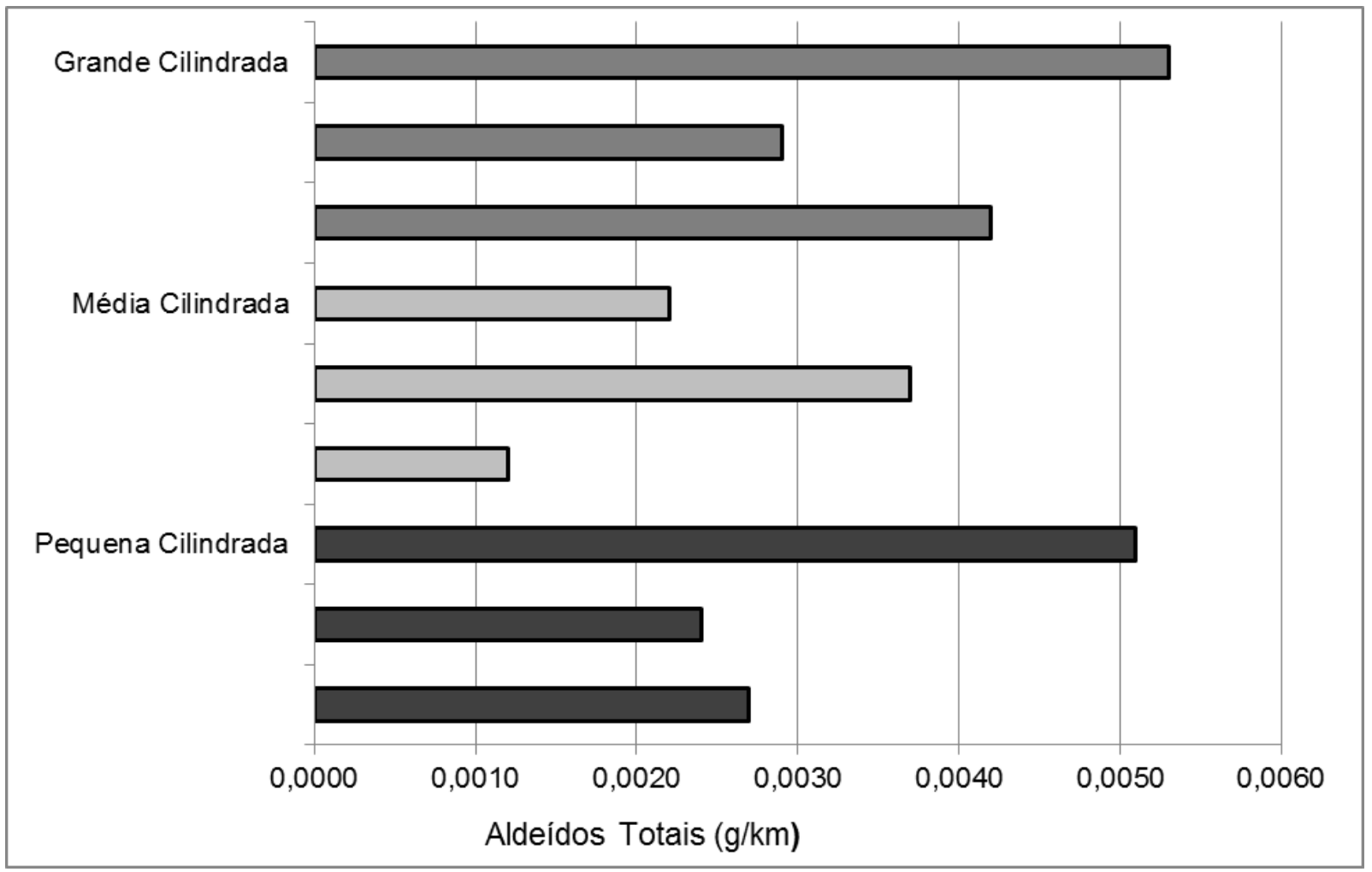

Figura 3: Resultados de emissões de aldeídos totais em $\mathrm{g} / \mathrm{km}$ das motocicletas ensaiadas

Foram feitas também a tabulação dos dados das motocicletas ensaiadas por aldeídos individuais (formaldeído e acetaldeído) em gramas por quilômetro, conforme Tabela 5, abaixo: 
Tabela 5: Resultados obtidos dos aldeídos individuais das motocicletas ensaiadas

\begin{tabular}{|c|c|c|}
\hline Categoria & $\begin{array}{c}\text { Formaldeído } \\
(\mathrm{g} / \mathrm{km})\end{array}$ & $\begin{array}{c}\text { Acetaldeído } \\
(\mathrm{g} / \mathrm{km})\end{array}$ \\
\hline Motocicleta & 0,0004 & 0,0022 \\
Pequena Cilindrada & 0,0004 & 0,002 \\
& 0,0006 & 0,0045 \\
\hline \multirow{3}{*}{ Média Cilindrada } & 0,0004 & 0,0008 \\
& 0,0014 & 0,0024 \\
Grande Cilindrada & 0,0007 & 0,0015 \\
\hline & 0,0016 & 0,0026 \\
& 0,0010 & 0,0019 \\
& 0,0015 & 0,0039 \\
\hline
\end{tabular}

A Tabela 5 mostra que as motocicletas de grande cilindrada também são maiores emissoras de formaldeído em relação as motocicletas de pequena cilindrada e maior parte das motocicletas de média cilindrada, os valores variaram de 0,0015 a $0,0016 \mathrm{~g} / \mathrm{km}$.

Nota-se também que uma parte das motocicletas de média cilindrada emitiram um valor mais alto que as demais de sua própria categoria, o valor encontrado foi de $0,0014 \mathrm{~g} / \mathrm{km}$.

A Figura 4 abaixo, mostra graficamente estas diferenças.

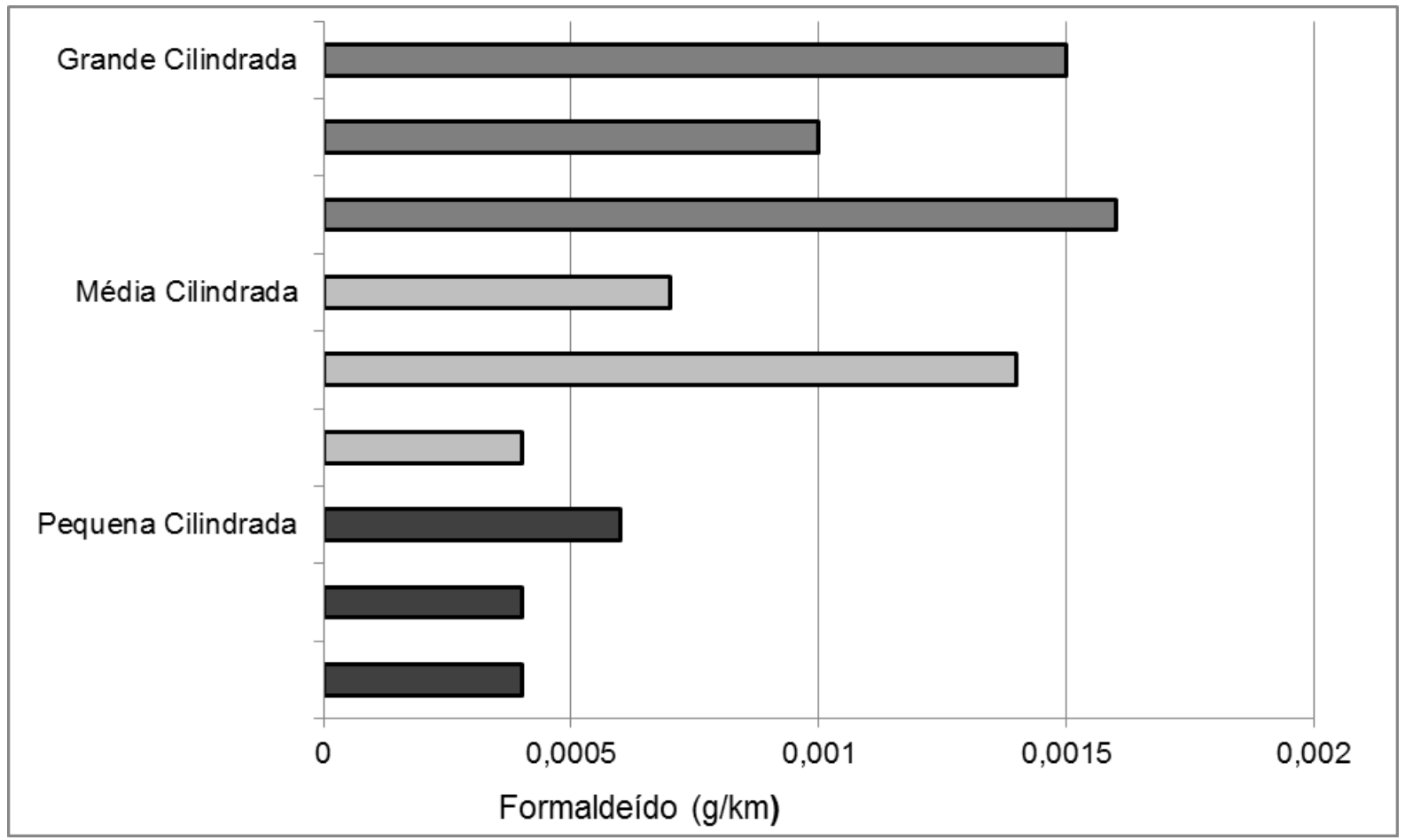

Figura 4: Resultados de emissões de formaldeído em $\mathrm{g} / \mathrm{km}$ das motocicletas ensaiadas 
Em relação aos resultados de emissões de acetaldeído em $\mathrm{g} / \mathrm{km}$, a Tabela 5 mostra que uma das motocicletas de pequena cilindrada foi a maior emissora deste composto, o valor encontrado foi de $0,0045 \mathrm{~g} / \mathrm{km}$.

As motocicletas de grande cilindrada também tenderam a emitir valores mais altos em relação as motocicletas de média cilindrada e parte das motocicletas de pequena cilindrada, os valores encontrados variaram de 0,0026 a 0,0039 g/km.

Observa-se que uma das motocicletas de média cilindrada também emitiu um valor significativo, em relação as motocicletas de sua própria categoria, o valor encontrado foi de $0,0024 \mathrm{~g} / \mathrm{km}$.

A Figura 5 mostra graficamente as diferenças encontradas.

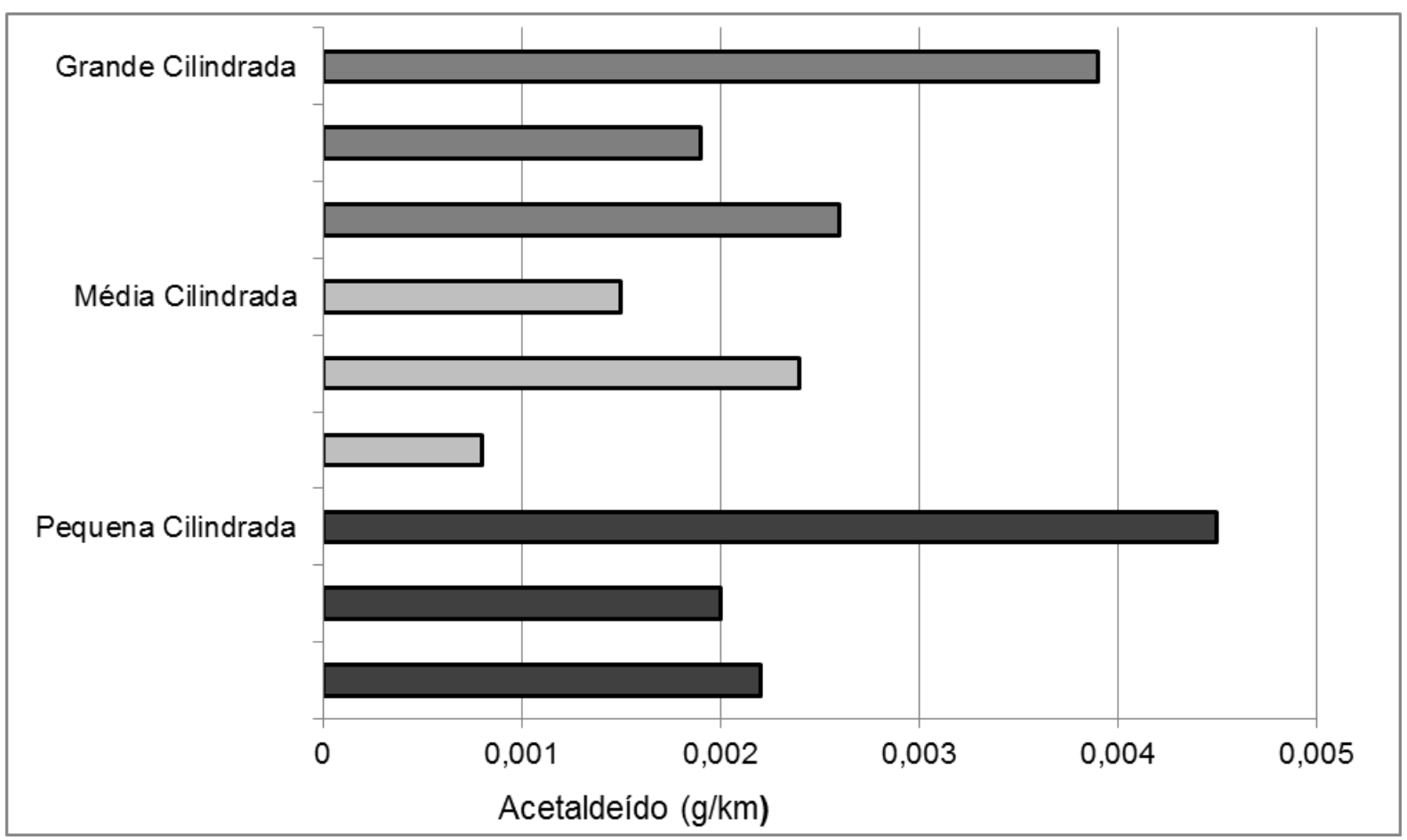

Figura 5: Resultados de emissões de acetaldeído em g/km das motocicletas ensaiadas

Por fim, foi realizado um comparativo das emissões de aldeídos totais em gramas por quilômetro das motocicletas ensaiadas em relação ao limite legal de emissões de aldeídos totais dos veículos leves, conforme Figuras 6 e 7 abaixo: 


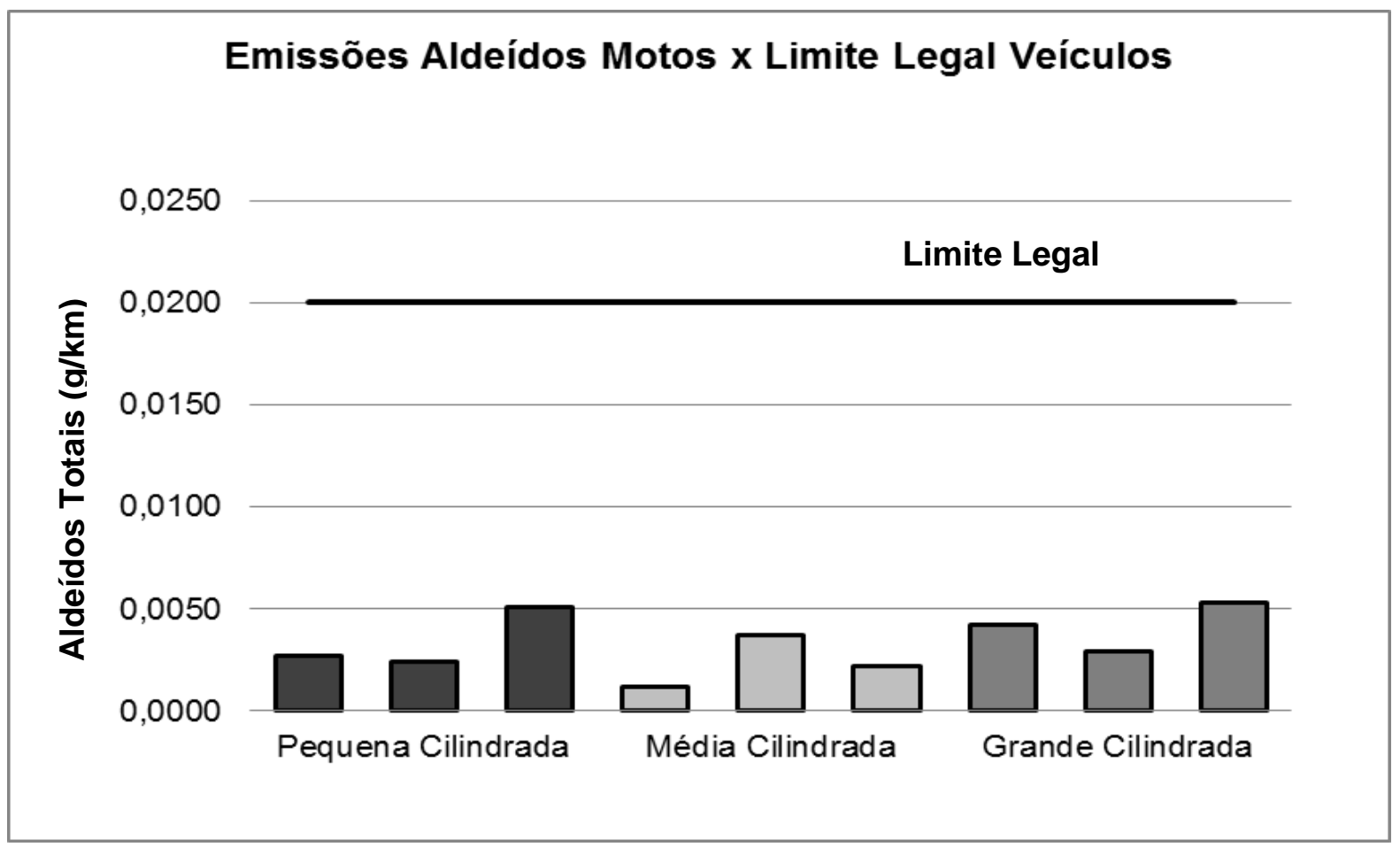

Figura 6: Comparativo das emissões de aldeídos totais das motocicletas ensaiadas em relação ao limite legal em gramas por quilômetro

A Figura 6 mostra que as emissões de aldeídos totais em gramas por quilômetro das motocicletas ensaiadas estão muito abaixo do Limite Legal em vigor para os veículos leves.

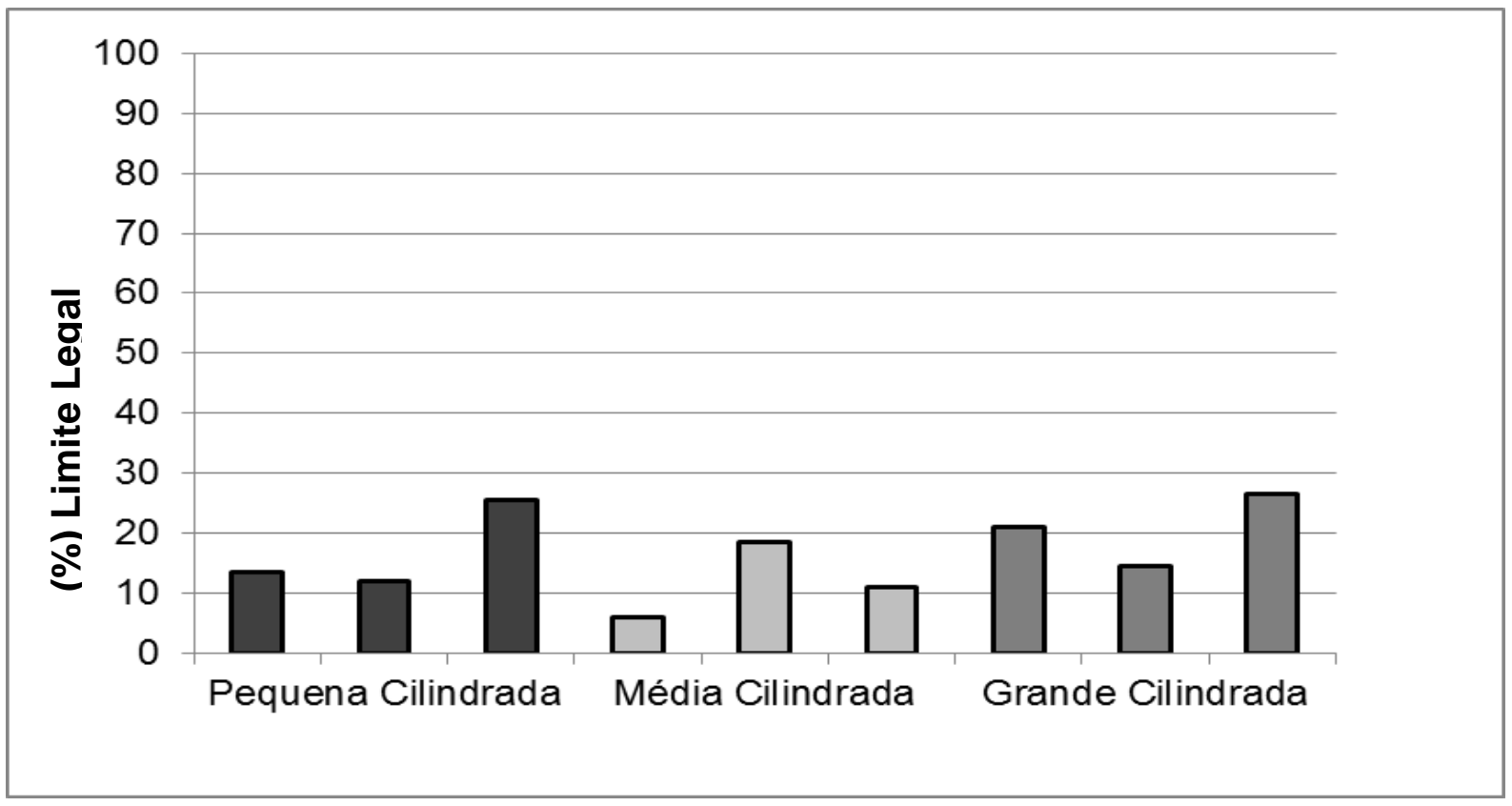

Figura 7: Comparativo das emissões de aldeídos totais das motocicletas ensaiadas em percentual 
$\mathrm{Na}$ figura 7, pode se notar que as maiores emissões de aldeídos encontradas nas motocicletas ensaiadas estão cerca de $30 \%$ abaixo do limite legal em vigor para os veículos leves, demonstrando que as mesmas atenderiam com facilidade.

\section{CONCLUSÃO}

As emissões de aldeídos totais e individuais (formaldeído e acetaldeído) foram maiores nas motocicletas de grande cilindrada, como era de se esperar. Isto se deve aos seus motores de maior capacidade volumétrica que emitem mais hidrocarbonetos totais em relação as demais, além disso, vale ressaltar que o ciclo de condução a ser seguido é mais extenso e a velocidade máxima atingida é superior, sendo necessário percorrer o ciclo 3 sem redução.

Uma parte das motocicletas de pequena cilindrada emitiram valores significativos de aldeídos totais. Isto também se refletiu nas emissões de acetaldeído destas motocicletas. Os valores obtidos já eram esperados, pois estas motocicletas apresentam o sistema de alimentação diferente das demais, utilizando-se de carburador.

As emissões de aldeídos totais e individuais (formaldeído e acetaldeído) de algumas motocicletas de média cilindrada apresentaram valores discrepantes quando comparadas as de sua categoria. Isto se deve ao fato de estarem ainda em desenvolvimento.

Para confirmação das tendências apresentadas por este trabalho, estudos devem ser realizados com maior número de motocicletas possivel.

Quando comparada as emissões de aldeídos totais encontradas nas motocicletas usadas nesse estudo em relação ao limite legal de veículos praticado hoje, todas atenderiam com facilidade.

\section{AGRADECIMENTOS}

A Magneti Marelli e a equipe do laboratório de Motos e Orgânicos.

\section{REFERÊNCIAS}

[1] IBAMA. Programa de Controle da Poluição do Ar por Veículos Automotores. Resolução Conama no 18 de 17.06.1986, pp. 40-59, 2011.

[2] IBAMA. Programa de Controle da Poluição do Ar por Veículos Automotores. Resolução Conama no 03 de 25.08.1989, pp. 60-61, 2011.

[3] IBAMA. Programa de Controle da Poluição do Ar por Veículos Automotores. Resolução Conama no 297 de 15.03.2002, pp. 205-218, 2011.

[4] EUROPA. Diretiva 97/24/CE do Parlamento Europeu e do Conselho, 1997. 
[5] IBAMA. Programa de Controle da Poluição do Ar por Veículos Automotores. Resolução Conama no 432 de 17.07.2011, pp. 298-305, 2011.

[6] EUROPA. Diretiva ECE/TRANS/180/Add.2, World Motorcycle Test Cycle WMTC, 2005.

[7] ABNT NBR 16369 - Motociclos e veículos similares - Determinação de hidrocarbonetos, monóxido de carbono, óxidos de nitrogênio e dióxido de carbono no gás de escapamento, 2015.

[8] ABNT NBR 8689 - Veículos rodoviários automotores leves - Combustíveis para ensaio - Requisitos, 2012.

[9] ABNT NBR 12016 - Veículos rodoviários automotores leves - Determinação de aldeídos e cetonas contidos no gás de escapamento, por cromatografia líquida - Método DNPH, 2009. 